RUNNING HEAD: AUDITORY CONTRIBUTIONS TO FOOD PERCEPTION

\title{
Introduction to the Special Issue:
}

\section{Auditory contributions to food perception and consumer behaviour}

Prof. Charles Spence (University of Oxford),

Dr. Felipe Reinoso-Carvalho (Universidad de los Andes School of Management, Bogota, Colombia),

Dr. Carlos Velasco (Department of Marketing, BI Norwegian Business School, Norway), \& Dr. Qian Janice Wang (Department of Food Science, Aarhus University, Denmark)

Submitted to: Multisensory Research

Date: May, 2018

WORD COUNT: 2,600 WORDS

CORRESPONDENCE TO: Prof. Charles Spence, Department of Experimental Psychology, Anna Watts Building, University of Oxford, Oxford, OX2 6GG, UK. E-mail: charles.spence@psy.ox.ac.uk 


\section{Introduction to the Special Issue}

What we hear before and/or while we eat/drink affects our taste/flavour experiences, even if we don't realize it. While there has been a long history of sensory science research investigating the impact of food sounds during consumption (see Spence, 2015, for a review), the focus of this special issue is rather on the product-extrinsic, or contextual/situational, cues such as music and ambient soundscapes, that have also been shown to influence what we expect, what we choose to buy/order in shops, restaurants, cafes, and bars, and how satisfied we are, as well as the perception we have of what we eat and drink (e.g., Biswas, Lund, \& Szocs, 2018; Feinstein, Hinskton, \& Erdem, 2002; Novak, La Lopa, \& Novak, 2010; Septianto, 2016; Spence, 2012; Zellner, Geller, Lyons, Pyper, \& Riaz, 2017).

One area of particular interest for the present Special Issue relates to the recent emergence of a growing body of literature on the topic of 'sonic seasoning' (Spence, 2017): This is where music/soundscapes are especially chosen, or else designed/composed, in order to correspond to, and hence hopefully to modify the associated taste / aroma / mouthfeel / flavour in food and beverages (e.g., Crisinel, Cosser, King, Jones, Petrie, \& Spence, 2012; Reinoso Carvalho Van Ee, Rychtarikova, Touhafi, Steenhaut, Persoone, Spence, \& Leman,2015; Wang \& Spence, 2016). Sonic seasoning, then represents one strand of research on the crossmodal correspondences (see Spence, 2011, for a review). Interesting questions here concern where, exactly, such surprising crossmodal correspondences originate from, and the conditions under which they influence tasting experiences and eating/drinking behaviours - e.g., as a function of congruency (when music and flavour correspond or not; e.g., Muniz, Harrington, Ogbeidea, \& Seo, 2017), or when compared while eating in silence (e.g., Hauck \& Hecht, 2019; Höchenberger \& Ohla, 2019; Lowe, Ringler, \& Haws; 2019, Watson \& Gunter, 2017). Cognitive neuroscientists are slowly starting to turn their attention to the neural consequences/underpinnings of such 'almost-synaesthetic' crossmodal interactions (Callan, Callan, \& Ando, 2018).

One branch of the literature on sonic influences on tasting has also examined the phenomenon of 'sensation transference' - addressing questions such as 'If you like the music more, do you like what you are eating/drinking more too?' (e.g., see Kantono, Hamid, Sheperd, Yoo, Carr, \& Grazioli. 2015; Kantono, Hamid, Sheperd, Yoo, Grazioli, \& Carr, 2016; Wang \& Spence, 2018; cf. Fritz, Brummerloh, Urquijo, Wegner, Reimer, Gutekunst, Schneider, Smallwood, \& 
Villringer, 2017). The latter phenomenon, note, appears elsewhere in the multisensory literature under the label 'affective ventriloquism' (see Spence \& Gallace, 2011).

Not only can the music and soundscapes affect the tasting experience, but a growing body of research shows that loud background noise ${ }^{1}$, be it airplane noise, white noise, or restaurant noise, affects both the taste of food and drink (e.g., higher levels of noise reduce sweetness perception; Yan \& Dando, 2015), as well as people's ability to discriminate various aspects of their tasting experience (see Spence, 2014a, for a review). Given the increasing presence of noise in many restaurants, cafes, and bars these days, this area of research may well have public health implications: Just take the finding that noise levels correlate with both greater rates of consumption (e.g., Guéguen, Jacob, Le Guellec, Morineau, \& Lourel, 2008; Guéguen, Le Guellec, \& Jacob, 2004; Kaiser, Silberger, Hilzendegen, \& Stroebele-Benschop, 2016), and a tendency to make unhealthy food choices (Biswas, Lund, \& Szocs, 2018). Indeed, given the observation that what we hear can influence what we taste, one may consider sound as a relevant design element of food and beverage experiences - What chef Heston Blumenthal presumably had in mind when once he was quoted as saying 'Sound is the forgotten flavour sense' (see Spence, Shankar, \& Blumenthal, 2011).

Here, it is important to note that the auditory inputs influencing our perception of what we eat/drink/taste are not limited to environmental sounds. They also involve the sounds that we produce while eating, such as slurping, crunching, or lip-smacking (Youssef, Youssef, Juravle, \& Spence, 2017; see Spence, 2015, for a review), as well as speech sounds that we use to refer to specific foods (e.g., Spence, 2014b). The sounds that are associated with food containers, such as product packaging, are also relevant to tasting and decision-making (e.g., see Spence \& Wang, 2015; Wang \& Spence, 2018). In many cases, such containers are a key part of the food experience itself, presumably through their role in setting expectations around the tasting experiences that are to come.

Given the growing literature on music and soundscape's influence on the multisensory tasting experience, there is a growing interest in using technology to synchronize auditory stimulation with the tasting experience (see Velasco, Reinoso-Carvalho, Petit, \& Nijholt, 2016; Spence, 2019a, for a review). Product extrinsic auditory-taste interactions are undoubtedly a rich area for creative practice, as evidence by The Chocolate Symphony presented by Maxime Goulet at

\footnotetext{
${ }^{1}$ When what we hear becomes too loud, it is usually regarded as noise.
} 
the 2018 IMRF meeting held in Toronto (see http://symphonicchocolates.com/; www.maximegoulet.com). Conference delegates were invited to taste four chocolates while listening to four special compositions, each one designed to correspond with the taste/flavour of one of the chocolates (always caramel, dark chocolate, mint, coffee).

Despite its inauspicious beginnings 70 years ago (see Pettit, 1958), research on atmospheric auditory contributions to food perception and behaviour has exploded in recent years, with interest coming from the fields of cognitive neuroscience, marketing, food science, gastronomy, design, branding, public health and beyond. In particular, in the present special issue, we called for papers studying the influence of auditory cues on food perception and consumer behaviour. Our aim was to put together a series of papers that would represent the state of the art of multisensory basic and applied research on the topic. In total, seven manuscripts were accepted for publication on the topic. Below, we present a short overview of these contributions.

\section{$\underline{\text { Outline of papers }}$}

In the opening paper, Spence et al. provide an overview of the literature concerning how extrinsic auditory cues, focusing specifically on food-unrelated auditory cues, can affect what we taste. In particular, the review covers key themes such as the influence of background noise and background music in food and drink experiences, as well as the role of sensation transfer and crossmodal correspondences. Next, Reinoso-Carvalho, Dakduk, Wagemans, and Spence, provide evidence to show how affective transfer influences the perceived taste, and pleasantness of beers. These researchers report a series of experiments in which such crossmodal effects were analyzed when two contrasting music tracks (positive vs. negative emotion) were presented to consumers while tasting beer. The results suggest that the emotional reactions triggered by the music influenced specific sensory and hedonic aspects of the multisensory tasting experience.

Speed, Peters, and Croijmans present a study designed to assess the effect of sound-odor congruency on participants' attitudes and memory for familiar and unfamiliar brands. Their results suggest that the level of arousal evoked by both auditory and olfactory cues is important when it comes to brand recognition. In particular, when participants were presented with high 
arousal sounds and smells together, participants were faster at recognizing the brands, relative to the other experimental conditions. This research then adds to the literature on how affective congruence between sensory cues can influence the way in which consumers interact with brands. Motoki and colleagues continue on the marketing theme, reporting on a series of studies demonstrating how the growing knowledge concerning crossmodal correspondences between audition and gustation can be used in a marketing context to change what consumers choose/think about the food products that they choose.

Thereafter, Fiegel et al. consider the influence of various parameters of auditory stimuli, including pitch, tempo, and volume levels of music in order to determine how they affect people's sensory perception and acceptance of foods (chocolate and bell peppers). Overall, the results revealed that the participants liked the foods more when music stimuli were perceived as more pleasant and stimulating, and that the flavor of the foods was perceived as more intense when the participants were more stimulated by the music samples that they heard. Relevant questions remain here concerning the 'relative' versus 'absolute' nature of crossmodal correspondences involving auditory stimuli (see Spence, 2019b).

Multisensory flavour perception is not a unitary and static experience. Rather is is often a complex and time-evolving experience. Techniques from sensory science such as Rate-AllThat Apply (RATA) and Temporal Dominance of Sensations (TDS) are increasingly enabling researchers to assess the various sensations that are experienced during a mouthful of fine wine, say. In the final two articles, Burzynska and colleagues (this volume), and Wang et al. (this volume) used such sensory methods to investigate the influence of sound on wine perception. Namely, Burzynska et al. evaluated the influence of high and low pitch on the perceived body, acidity, and intensity of two red wines whose flavour profiles were validated using RATA. On the other hand, Wang et al. used TDS to show that the temporal changes in flavours perceived in a mouthful of wine can be synchronised to changes in the background music.

\section{Conclusions}

In conclusion, sound and food is an exciting field with the potential to encourage collaboration across multiple disciplines, to enhance our theoretical understanding of multisensory flavour perception, as well as, potentially, to create applications with wider societal impact. With time, as the empirical literature and interest in this topic continues to grow, the underlying 
mechanisms that explain such surprising crossmodal associations and influences are starting to be disentangled. New methods and techniques are being successfully adopted, bringing novel insights to the field, and as we have seen, marketing \& management are adopting these topics as relevant in the corresponding basic research literatures (e.g., open call for papers at the Journal of Business Research).

\section{REFERENCES}

Biswas, D., Lund, K., \& Szocs, C. (2018). Sounds like a healthy retail atmospheric strategy: Effects of ambient music and background noise on food sales. Journal of the Academy of Marketing Science, 47, 37-55.

Callan, A., Callan, D., \& Ando, H. (2018). Differential effects of music and pictures on taste perception -an fMRI study. Poster presented at the Annual Meeting of the International Multisensory Research Forum. June, 14-17 ${ }^{\text {th }}$ June, Toronto, CA.

Crisinel, A.-S., Cosser, S., King, S., Jones, R., Petrie, J., \& Spence, C. (2012). A bittersweet symphony: Systematically modulating the taste of food by changing the sonic properties of the soundtrack playing in the background. Food Quality and Preference, 24, 201-204.

Feinstein, A., Hinskton, T., \& Erdem, M. (2002). Exploring the effects of music atmospherics on menu item selection. Journal of Foodservice Business Research, 5(4), 3-25.

Fritz, T. H., Brummerloh, B., Urquijo, M., Wegner, K., Reimer, E., Gutekunst, S., Schneider, L., Smallwood, J., \& Villringer, A. (2017). Blame it on the bossa nova: Transfer of perceived sexiness from music to touch. Journal of Experimental Psychology: General, 146, 1360-1365.

Guéguen, N., Jacob, C., Le Guellec, H., Morineau, T., \& Lourel, M. (2008). Sound level of environmental music and drinking behavior: A field experiment with beer drinkers. Alcohol. Clinical \& Experimental Research, 32, 1-4.

Guéguen, N., Le Guellec, H., \& Jacob, C., (2004). Sound level of background music and consumer behavior: An empirical evaluation. Perceptual \& Motor Skills, 99, 34-38.

Hauck, P., \& Hecht, H. (2019). Having a drink with Tchaikovsky: The crossmodal influence of background music on the taste of beverages. Multisensory Research, 32, 1-24.

Höchenberger, R., \& Ohla, K. (2019). A bittersweet symphony: Evidence for taste-sound correspondences without effects on taste quality-specific perception. Journal of Neuroscience Research, 97, 267-275.

Kaiser, D., Silberger, S., Hilzendegen, C., \& Stroebele-Benschop, N. (2016). The influence of music type and transmission mode on food intake and meal duration: An experimental study. Psychology of Music, 44, 1419-1430.

Kantono, K., Hamid, N., Sheperd, D., Yoo, M. J. Y., Carr, B. T., \& Grazioli, G. (2015). The effect of background music on food pleasantness ratings. Psychology of Music, 13, 1-15.

Kantono, K., Hamid, N., Sheperd, D., Yoo, M. J. Y., Grazioli, G., \& Carr, T. (2016). Listening to music can influence hedonic and sensory perceptions of gelati. Appetite, 100, 244-255. 
Lowe, M., Ringler, C., \& Haws, K. (2018). An overture to overeating: The cross-modal effects of acoustic pitch on food preferences and serving behaviour. Appetite, 123, 128-134.

Muniz, R., Harrington, R. J., Ogbeidea, G.-C., \& Seo, H.-S. (2017). The role of sound congruency on ethnic menu item selection and price expectations. International Journal of Hospitality \& Tourism Administration, 18, 245-271.

Novak, C. C., La Lopa, J., \& Novak, E. R. (2010). Effects of sound pressure levels and sensitivity to noise on mood and behavioral intent in a controlled fine dining restaurant environment. Journal of Culinary Science \& Technology, 8, 191-218.

Pettit, L. A. (1958). The influence of test location and accompanying sound in flavor preference testing of tomato juice. Food Technology, 12, 55-57.

Reinoso Carvalho, F., Van Ee, R., Rychtarikova, M., Touhafi, A., Steenhaut, K., Persoone, D., Spence, C., \& Leman, M. (2015). Does music influence the multisensory tasting experience? Journal of Sensory Studies, 30(5), 404-412.

Septianto, F. (2016). "Chopin" effect? An exploratory study on how musical tempo influence consumer choice of drink with different temperatures. Asia Pacific Journal of Marketing and Logistics, 28, 765-779.

Spence, C. (2011). Crossmodal correspondences: A tutorial review. Attention, Perception, \& Psychophysics, 73, 971-995.

Spence, C. (2012). Auditory contributions to flavour perception and feeding behaviour. Physiology \& Behaviour, 107, 505-515. http://dx.doi.org/10.1016/j.physbeh.2012.04.022

Spence, C. (2014a). Noise and its impact on the perception of food and drink. Flavour, 3:9.

Spence, C. (2014b). Assessing the influence of shape and sound symbolism on the consumer's response to chocolate. New Food, 17 (2), 59-62.

Spence, C. (2015). Eating with our ears: Assessing the importance of the sounds of consumption to our perception and enjoyment of multisensory flavour experiences. Flavour, $4: 3$.

Spence, C. (2017). Sonic seasoning. In L. Minsky \& C. Fahey (Eds.), Audio branding: Using sound to build your brand (pp. 52-58). London, UK: Kogan Page.

Spence, C. (2019a). Multisensory experiential wine marketing. Food Quality \& Preference, 71, 106-116.

Spence, C. (2019b). On the relative nature of (pitch-based) crossmodal correspondences. Multisensory Research, 32, 235-265.

Spence, C., \& Gallace, A. (2011). Multisensory design: Reaching out to touch the consumer. Psychology \& Marketing, 28, 267-308.

Spence, C., Shankar, M. U., \& Blumenthal, H. (2011). 'Sound bites': Auditory contributions to the perception and consumption of food and drink. In F. Bacci \& D. Melcher (Eds.), Art and the senses (pp. 207-238). Oxford, UK: Oxford University Press.

Spence, C., \& Wang, Q. (J.) (2015). Sensory expectations elicited by the sounds of opening the packaging and pouring a beverage. Flavour, 4:35.

Velasco, C., Reinoso-Carvalho, F., Petit, O., \& Nijholt, A. (2016). A multisensory approach for the design of food and drink enhancing sonic systems. In Proceedings of the 1st Workshop on Multi-sensorial Approaches to Human-Food Interaction (MHFI'16), A. Nijholt, C. Velasco, G. Huisman, \& K. Karunanayaka (Eds.). ACM, New York, NY, Article 7, 7 pages. 
Wang, Q. (J.) \& Spence, C. (2016). "Striking a sour note": Assessing the influence of consonant and dissonant music on taste perception. Multisensory Research, 30, 195-208.

Wang, Q. (J.), \& Spence, C. (2018). 'A sweet smile': The modulatory role of emotion in how extrinsic factors influence taste evaluation. Emotion and Cognition, 32, 1052-1061.

Wang, Q. J., \& Spence, C. (2018). Sonic packaging: How packaging sounds influence multisensory product evaluation. In C. Velasco \& C. Spence (Eds.), Multisensory packaging: Designing new product experiences. Cham, Switzerland: Palgrave MacMillan.

Watson, Q. J., \& Gunter, K. L. (2017). Trombones elicit bitter more strongly than do clarinets: A partial replication of three studies of Crisinel and Spence. Multisensory Research, 30(3-5), 321-335.

Yan, K. S., \& Dando, R. (2015). A crossmodal role for audition in taste perception. Journal of Experimental Psychology: Human Perception \& Performance, 41, 590-596.

Youssef, J., Youssef, L., Juravle, G., \& Spence, C. (2017). Plateware and slurping influence regular consumers' sensory discriminative and hedonic responses to a hot soup. International Journal of Gastronomy \& Food Science, 9, 100-104.

Zampini, M., \& Spence, C. (2004). The role of auditory cues in modulating the perceived crispness and staleness of potato chips. Journal of Sensory Science, 19, 347-363.

Zellner, D., Geller, T., Lyons, S., Pyper, A., \& Riaz, K. (2017). Ethnic congruence of music and food affects food selection but not liking. Food Quality \& Preference, 56 (Part A), 126129. 